\title{
IGUALDADE E INCLUSÃO SOCIAL: estudo de casos concretos no sistema educacional'
}

\author{
Fernando Dias Menezes de Almeida
}

\begin{abstract}
Resumo:
Partindo de considerações gérais sobre liberdade e igualdade como fundamentos do Estado democrático, o presente estudo desenvolve, como objeto especifico, o tema da igualdade e das ações afirmativas visando à inclusão social, aplicado ao sistema educacional. Fixadas premissas teóricas da matéria, são apresentados estudos de ações execuladas pelo listado em casos concretos, envolvendo o ensino acadêmico universitário e o ensino profissional.
\end{abstract}

Palavras-chave: Ensino Superior. Universidades. Ensino Profissional. Igualdade. Inclusão Social. Ações Afirmativas.

\begin{abstract}
:
Starting from general considerations about liberty and equality as the basis of the democratic State. this paper refers to equality and affirmative actions towards social inclusion, applied to the educational system. Considering theoretical premises, case studies are presented, based on State policies involving academic and professional education.
\end{abstract}

Keywords: High Education. Universities. Professional Education. Fquality. Social Inclusion. Affirmative Actions.

I. Introdução: liberdade e igualdade

Mais uma vez live a honra de receber o convite do Instituto Pimenta Bueno para integrar uma das mesas de seu tradicional Encontro de Direito Constitucional, ao lado de meus ilustres mestres, razão pela qual agradeço ao seu presidente. professor Manoel Gonçalves Ferreira Filho.

Lstamos, neste Painel, a tratar, em essência, do tema da igualdade, que, ao lado da liberdade, é "expressão direta da democracia" para citar Ferreira Filho."

\footnotetext{
I Irabalho originalmentc exposto durante o $13^{\circ}$ Encontro Nacional de Direito Constitucional, promovido pelo Instituto Pimenta Bueno - Associação Brasileira dos (onstiłucionalistas. nos dias 1 y a 21 de agosto de 2004. na Faculdade de Direito da Universidade de São Paulo. Os dados estatísticos apresentados neste estudo foram atualizados para a publicação.

Professor Doutor do Departamento de Direito do Estado da Faculdade de Direito da USP. Secretário Adjunto da Ciência. Tecnologia e Desenvolvimento Econômico do Estado de São Paulo.

FERREIRA FILHO. Manoel Gonçalves. Curso de Direito Constilucional. São Paulo: Saraiva, 1997. p. 273.
} 
Nas palavras de Bobbio," assim "como 'liberdade 'igualdade tem predominantemente na linguagem politica um significado emotivo positivo, quer dizer, designa algo que se deseja"

Essa irmanação de liberdade e igualdade, como pilares da democracia, assim como sua valuração positiva na apreciação da generalidade dos indivíduos, não impede que, em situações extremas, se identifique uma "tensão inelutável entre liberdade $c$ igualdade", como bem observa Jorge Miranda. ${ }^{4}$ De fato, se "levado às últimas conseqüencias, um princípio radical de liberdade oblitera a igualdade da condição humana e, em contrapartida, um principio de igualdade igualitária esmaga u autonomia pessoal. Porém, em concreto, clas andam constantemente a par, uma implicando a outra."

Parece interessante o mote do tratamento paralelo de liberdade e igualdade para impulsionar o início deste istudo. Siga-se, nesse sentido, a análise de Bobbio.

Assim como ocorre com "liberdade" também se encontra razoável grau de dificuldade para a compreensão precisa do significado de "igualdade" Porém, se quanto a "liberdade" a dificuldade decorre da ambigüidade do termo - ou seja, fala-se, em linguagem política. de "liberdade" ao menos em dois significados distintos: liberdade positiva e liberdade negativa" - quanto a "igualdade" a dificuldade reside na indeterminação do termo - isto é, "dizer que dois entes são iguais, sem outra determinação, nada significa na linguagem política, se não se especifica de que entes se trata e a respeito de que coisa são iguais" "

Com efeito, se, de um lado, "liberdade" é uma qualidade da pessoa, de outro, "igualdade" é "pura e simplesmente uin tipo de relação formal, que se pode preencher pelos mais diversos contezidos" 7 Desse modo. há sentido na proposição "fulano é livre", mas não há nenhum sentido na proposição "fulano é igual" sem que sc indique "igual a quem" e "igual em quê"

Corolário dessa idéia é compreender-se a liberdade como um bem, um valor para o indivíduo enquanto indivíduo. Já a igualdade seria um bem ou um valor para os

\footnotetext{
BOBBIO, Norberto. Igualdad y liberlad. Trad. Pedro Aragón Rincón. Barcelona: Paidós, 1993. p 53.

MIRANDA, Jorge. Manual de Direito Constitucional Coimbra: Coimbra, 2000. Tomo IV. p. 224.

5 O tema é desenvolvido por Bobbio na mesma obra ora citada, p. 97 e seguintes. Sobre liberdade positiva e liberdade negativa ver ainda BERLIN. Isaiah. Dois Conceitos de Liberdade. In: Quatro Ensaios sobre a Liberdade. Trad. Wamberto Hudson Ferreira. Brasilia: Universidade de Brasília, 1981. Em síntese, a liberdade negativa seria a liberdade de agir, a liberdade que permite ao seu sujeito fazer ou nào fazer algo sem que sofra coerçăo; enquanto a liberdade positiva seria a liberdade de querer, a liberdade que permite ao seu sujeito tonar decisões segundo sua própria vontade. Trabalhei com esses conceitos im meu Liberdade de Reunião. São Paulo: Max 1,imonad, 2001. p. 19-29.
}

- BOBBIO, Norberto. Igualdady Liberlud. Trad. Pedro Aragón Rincón. Barcelona: Paidós, 1993. p. 53-54.

7 Id., ibid., p. 54. 
componentes individuais de um todo, enquanto se relacionem entre si. Igualdade, assim, pressupõe que haja uma coletividade e que se estabeleçam relações entre os membros da coletividade. $^{8}$

Oportuna, neste ponto, a ubservação de Peces-Barba, ${ }^{9}$ no sentido de ser a liberdade o valor central que se apresenta como fundamento dos direitos humanos. Sendo assim, a igualdade, como fundamento desses mesmos direitos, poderia avançar até o ponto em que potencialize a liberdade, devendo deter-se no momento em que possa limitá-la ou prejudicá-la. A igualdade, desse modo, segundo o autor, teria o sentido de "criar as condições materiais para uma liberdade possivel para todos"

Liberdade como valor central dos direitos humanos. Liberdade como qualidade essencial do individuo. E igualdade como relação essencial entre indivíduos em um Estado democrático. Igualdade como meio de se garantir liberdade a todos. Com esses pressupostos, inicie-se a análise do tema especifico proposto para este estudo.

2. Igualdade e açõus afirmativas no ensino superior

É desnecessário maior esforço para que se constatem as patentes desigualdades materiais - em especial pelo aspecto econômico - existentes na sociedade brasileira.

Tais desigualdades são notadas com particular ênfase no sistema de ensino superior.

Alguns números são interessantes para precisar aquilo que já é do conhecimento geral. Tome-se o exemplo do Estado de São Paulo, Estado que concentra um terço do PIB nacional, e que convive em larga escala com desigualdades sociais.

São Paulo, com uma população de mais de 39 milhões de habitantes, contava, conforme dados do Censo Escolar de 2003, ${ }^{10}$ com cerca de 1.050 milhões de alunos em cursos superiores de graduação presenciais, dos quais aproximadamente 163 mil alunos em escolas públicas (e gratuitas). "Isso significa $2.7 \%$ da população do Estado com acesso ao ensino superior; ou $0,4 \%$ da população com acesso ao ensino superior público. E, ainda assim, registre-se de passagem, o Estado de São Paulo apresenta números substancialmente superiores à média nacional.

\footnotetext{
BOBBIO, Norberto. Igualdad y Liberlad. Trad. Pedro Aragón Rincón. Barcelona: Paidós, 1993. p. 55-56.

PECES-BARBA, Gregorio. Curso de Derechos Fundamentales. Madrid: EUDEMA, 1991. p. 242.

Fonte: MECINEP/DAES (www.mec.gov.br).

96 mil em universidades ou faculdade estaduais; 57 mil em municipais; e 9 mil em federais.
} 
Para reverter essa situação, o Estado de São Paulo trata com especial atenção suas três universidades - USP, Unicamp e Unesp - destinando-lhes em 2005 mais de R.\$ 3.8 bilhões $^{12}$ (equivalentes a $9,57 \%$ da arrecadação do ICMS).

Outros dados que explicitam distorções em nosso sistema - e cujas causas históricas não cabe aqui analisar - são os que mostram a brutal inversão da participação do Poder Público, de um lado, nos ensinos fundamental e médio e, de outro, no ensino superior. Enquanto no ensino fundamental $86 \%$ das matrículas. no Estado de São Paulo, estão na rede pública, percentual que praticamente se mantém no ensino médio, apenas $15.5 \%$ das matrículas de ensino superior estão nas universidades ou faculdades públicas e $84,5 \%$ nas privadas.

Ora, considerando-se a circunstância de que o ensino superior público atualmentu possui grau de qualidade muito superior à média do ensino privado, mas que a rede pública de ensino fundannental e médio (única acessível à enorme parcela da população com inferiores condições econômicas) oferece, em média, formação de menor qualidade que escolas privadas, ¿ natural esperar que o maior percentual de ingréssantes nas universidades públicas sejam originários do ensino médio privado. Resta assim à grande massa dos egressos do ensino médio público buscar. se for esse o caso, vaga em faculdades privadas, o que muitas vezes resta impossivel, dados os custos envolvidos.

Verifiquem-se os percentuais de alunos das universidades estaduais paulistas originários do ensino médio público. São dados do vestibular de 2004: USP $27 \%$; Unicamp - 28\%; e Lnesp - 40\%. Agora os percentuais relativos à auto-declaração como ncgros (também vestibular 2004): USP - 11\%; Unicamp - 11\%; Unesp - 14\%. ${ }^{13}$

Dados como esses acima expostos, naturalmente vêm embasando, no Brasil. propostas de ações afirmativas tendentes à inclusão na universidade, em especial na universidade pública (pois custeada com recursos de toda a população), de segmentos da

12 Certamente que o papel das universidades públicas estaduais paulistas não é apunas o ensino de graduação. caracterizando-se as très universidades igualmente como universidades de pesquisa, ou seja. que concentram grande parte de seus recursos não apenas na transmissão. mas tambèm na geração do conhecimento científico. E o fazem com reconhecido grau de exccléncia.

13 A propósito, interessante verilicar a análise produzida por Carlos Henrique de Brito Cruz, no artigo "Universidade Pública - O Mito do Flitismo", publicado no jornal O Estado de S. Paulo, cm 18/01/2004. Nesse texto, a partir da Pesquisa Nacional por Amostragem de Domicílios (Pnad), realizada pelo IBGE portanto, dados rulativos à realidade nacional, e rão apenas paulista - o autor aponta que "em 2002, verificase que nas universidades publicas brasileiras $38 \%$ dos alunos vem de familias com renda per capita inferior a dois salários minimos. Nas universidades privadas essa faixa de renda abrange apenas $24 \%$ do alunado. Na faixa ahaixa de um salurio minimo, a incidência na universidade puiblica è mais que duas vezes maior do que nas instimições privadas. A situação se inverte na faixa de renda acima de dez salários mínimos: nas institnições privadas se encontram 9,5\% dos alunos e nas universidades públicas, apenas $5,4 \% . O$ quadio de maior inclusão nas instituições puibiicas se repete para a diversidade étnica. Segundo a mesma Pnad, no ensino superior público. $28 \%$ dos estuclantes se declararam pretos ou pardos (categorias do IBGE); 10 ensino superior privado. o porcentual cai para 15\%. praticamente a metade." 
população com condições econômicas menos favorecidas ou de segmentos da população negra e indigena.

Abra se um parêntese para esclarecer que, em princípio, as medidas voltadas à inclusão dos mais pobres nas universidades partem da defesa de valor diverso das medidas relativas à inclusão de negros e índios.

$\mathrm{Na}$ primeira hipótese, se está buscando dar um tratamento proporcionalmente desigual para indivíduos que se encontrem em diversa situação econômica. de modo a igualá-los.

$\mathrm{Na}$ segunda hipótese, se pretende reduzir desigualdades sociais historicamente constatadas entre a população branca e a população negra, parda ou indigena, acompanhadas ou-não de preconceitos e discriminações (em seu sentido negativo).

Todavia, para efeito da discussão da inclusão nas universidades, essa segunda hipótese não se aplica, ocorrendo apenas a primeira. De fato, um contingente maior de população negra não-ingressa na universidade, não porque haja preconccito contra ela no vestibular, mas porque, por notórias razões históricas, que agora não cabe aprofundar, há uma incidência proporcionalmente maior de pobreza entre a população negra, o mesmo valendo para índios.

Sendo assim, em matéria de inclusão no ensino superior, o que está em questão é a condição econômica dos interessados, pois, como já visto, a população mais rica. na atual conjuntura nacional. tem possibilidades substancialmente maiores de adquirir um bom preparo para enfrentar os exames vestibulares.

Fechado agora o parêntese, há que se registrar que, dentre as releridas ações afirmativas para inclusão social nas universidades. logo desponta a defesa da adoção de quotas de vagas reservadas para os egressos no ensino público; ou para negros e índios; ou ainda para negros e índios que cumulativamente sejam egressos do ensino público.

Note-se que o sistema de quotas ${ }^{14}$ cria uma espécie de dupla fila de entrada nas universidades, de modo que a competição pelas vagas correspondentes às quotas é distinta da competição pelas demais vagas. Esse sistema, evidentemente, retira ênfase do critério de mérito acadêmico como critério de seleção para ingresso no ensino superior.

Por outras palavras, o melhor candidato da competição pelas vagas de determinada quota (e que, portanto, ingressará na faculdade) pode, por hipótese, ter rendimento inferior a candidatos desclassificados na competição pelas demais vagas.

\footnotetext{
1 A análise que se segue tem por objeto o sistema de quotas para ingresso no ensino superior, independentemente de qual o segmento de população que visa a favorecer.
} 
O problema assim evidenciado remete à discussão do critério de justiça para que se dê tratamento de igualdade em matéria de ingresso nas universidades.

Mais uma vez invoca-se a análise de Bobbio's para esclarecer que a igualdade, enquanto relação entre dois entes é um fato neutro. Para que haja valoração na relação de igualdade, há que se distinguir a igualdade (ou desigualdade) justa da injusta: "a justiça é um ideal, a igualdade é um fato"

E essa distinção entre igualdado justa e injusta pressupõe que so eleja um "critério de justiça" São exemplos de critérios: "capacidade" "mérito" "necessidade" entre tantos outros. A escolha do critério não segue nenhuma regra preestabelecida, mas há que se dar com base em cada caso concreto objetivamente considerado, ainda que naturalmente essa objetividade seja impregnada por valores pessoais ou sociais do sujeito que escolhe. $^{16}$

Para se enfrentar a questão da igualdade e do critério de justiça para ingresso nas universidades. há que se partir da premissa de que a função essencial das universidades é a geração do conhecimento de nível superior, indispensável para o desenvolvimento, a prosperidade, entim, a própria soberania de um País. "Gcração de conhecimento" tanto no sentido do desenvolvimento da ciência, como no sentido da formação de pessoas preparadas para aplicá-la.

Portanto, o critério de acesso às universidades só pode ser o critério do mérito acadêmico, ou seja, do potencial intelectual de aprendizado e de geração de novos conhecimentos.

Frise-sc a idéia de "potencial intelectual de aprendizado e de geração de novos conhecimentos" Isso para desde já se afastar a idéia de que o critério de mérito deva se reduzir a exames vestibulares que meçam informações adquiridas ao longo da vida escolar do aluno, automaticamente reproduzidas em uma prova.

A igualdade justa, nesse caso, garante-se com exames vestibulares que objetivamente meçam esse potencial, aplicados universalmente a todos os candidatos, isto é, de modo a que todos os candidatos possam competir entre si para ingressar por uma mesma "fila"; e não por "filas" diferentes, como ocorreria pelo sistema de quotas. Essa tese. ora defendida em abstrato, está consagrada no Direito brasileiro vigente, nos termos do art. 208, V. da Constituição Federal:

Art. 208. O dever do Estado com a educação será efetivado mediante a garantia de:

I5 BOBBIO, Norberto. Igualdad y liberlad. Trad. Pedro Aragón Ríncón. Barcelona: Paidós, 1993. p. 59-64.

16 Observe-se que, exemplificando situaçōes em que predominantemente se aplicam curtos critérios, Bobbio menciona o critério do mérito como aquele empregado nas escolas para finalidades essencialmente selctivas (p. 63). 


\section{$(\ldots)$}

$\mathrm{V}$ - acesso aos niveis mais clevados do ensino, da pesquisa $\mathrm{e}$ da criação artística, segundo a capacidade de cada um:

Observe-se, para reforçar a interpretação - de resto razoavelmente evidente de que esse inciso $\mathrm{V}$ do art. 208 da Constituição Federal elege o mérito acadêmico como critério de justiça para ingresso no ensino superior, que os incisos I e II, do mesmo artigo, ao tratarem respectivamente dos ensinos fundamental e médio, referem-se à obrigatoriedade do primeiro, e à progressiva universalização do segundo, ou seja, prevendo acesso de todos os indivíduos a esses níveis de ensino, independentemente de qualquer outro critério.

Cabe ainda lembrar que também a Declaração Universal dos Direitos Humanos, ${ }^{1 ?}$ em seu art. XXVI, 1, adota expressamente o critério de mérito para acesso à instrução superior:

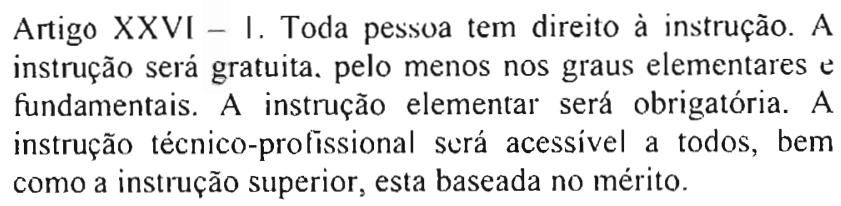

Considerar que as universidades são meio de ascensão econômica ou social o que circunstancialmente pode ser uma verdade na realidade brasileira - apenas evidencia a distorção da nossa sociedadc, que, em grande medida, somente reconhece valor e dá chance de progresso econômico a quem ostente o diploma universitário.

Daí duas decorrências em termos de ações imputáveis ao Poder Público, visando à inclusão social via sistema educacional:

a) há que se buscar garantir ao máximo condições de igualdade para que qualquer indivíduo que queira, possa competir para ingressar na universidade; e

b) há que se garan ir alternativas de sucesso pessoal e profissional fora da universidade para os indivíduos que, por motivos variados (v.g., vocação, opção por oportunidades de trabalho), não busquem a formação superior acadêmica, mas sim formação profissional de caráter básico, técnico ou tecnológico, que são igualmente importantes para o sucesso da nação, sem que aí haja qualquer julgamento quanto a uma opção ser mais valorosa que outra.

\footnotetext{
17 A provada pela Assembléia Geral das Nações Unidas em 1948.
} 
3. Fstudo de casos concretos: ensino acadêmico universitário e inclusão social

Quanto à primeira ordem de ações (item "a" supra). se há injustiças sociais que impedem que determinadas pessoas adquiram preparo para competir em siluação de igualdade para ingressar na universidade, há que se buscar corrigir essa desigualdade, ofurecendo preparo adequado a todos e aperfeiçoando mecanismos de vestibulares, sem abrir mão do critério de mérito acadêmico.

Criar modos artificiais para que elas ingressem não apenas deixa de combater as causas das tais injustiças, como ainda prejudica as universidades no desempenho de sua função de gerar conhecimento de excclência para o sucesso do País. Apenas para exemplificar com ações concretas que podem ser adotadas nesse sentido, vale citar, em primeiro lugar, medida bastante original implementada pela Universidade Estadual de Campinas - Unicamp, aperfeiçoando seu vestibular, sem abandonar o critério de mérito acadêmico.

O sistema adotado pela Unicamp $^{18}$ parte da constatação estatística de que os alunos originários do ensino público de nível médio têm melhor desempenho na universidade do que o originário do ensino privado que tenha obtido pontuação semelhante no vestibular.

Nesse sentido, a Unicamp decidiu conceder 30 pontos a mais para os vestibulandos que tenham cursado o ensino médio integralmente na rede pública; e mais I0 pontos para os que. vindo da rede pública, se declararem negros. (incluindo pardos) ou indios.

Considerando-se que a média de pontos para ingressar no vestibular tem se situado em torno de 530, essa pontuação extra é suficiente para apenas "desempatar" na margem próxima à nota de corte, de modo favorável aos alunos do ensino público, que, como dito, se sabe turão um melhor desempenho no futuro." Mas esse simples "desempate" faz muita diferença

Com a aplicação dessa medida no vestibular de $2005,{ }^{20}$ já registrou-se um aumento de $36 \%$ no número de aprovados oriundos de escolas públicas; e um aumento de $45 \%$ no número de estudantes autodeclarados pretos, pardos ou indígenas.

\footnotetext{
Que se encontra bem esclarecido no artigo "Inclusão Social com Valor Acadêmico", de autoria de seu Reitor, Carlos Henrique de Brito Cruz, publicado no jornal O Estado de S. Paulo. em 3.6.04. Os estudos estatisticos que embasaram cssas medidas encontram-se publicados no Jornal da I nicamp. edição de 31/05 a 06/06/2004. p. 6-7.

19 E que, por muito pouca diferença na pontuaçào, restariam fora da universidade, não fosse essa medida.

20 Dados da primeira chamada.
} 
O mais interessante é que a inclusão social foi ainda mais expressiva nos cursos mais procurados. Se considerarmos apenas os cinco cursos mais concorridos, ${ }^{21} \mathrm{o}$ aumento de oriundos da escola pública foi de $220 \%$ e o aumento de negros de $94 \%$. $^{22}$

Ademais, esses pontos só são acrescentados na $2^{a}$ fase do exame vestibular, ou seja, para aqueles que mostraram seu bom desempenho na $1^{\text {a }}$ fase. $E$ todos concorrem em um mesmo grupo (há apenas uma única fila de entrada), diferentemente do sistema de quotas.

Por todas essas razões, resta privilegiado, com esse mecanismo, o mérito acadêmico como critério para ingresso na universidade.

Mais uma ação que já apresentou resultados concretos altamente positivos de inclusão social no ensino superior, respeitando-se o critério do mérito acadêmico, foi a implantação do novo campus da USP na Zona Leste do Município de São Paulo. ${ }^{23}$

Essa região da Zona Leste da Capital é área reconhecidamente habitada por população com situação econômica menos favorecida, mas com enorme concentração urbana: 4,5 milhões de habitantes, sem que se considerem os moradores dos Municípios da 7.ona Leste da Região Metropolitana.

O simples fato de a USP fazer-se fisicamente presente na região, oferecendo 1.020 novas vagas em vestibular, ${ }^{24}$ para dez novos cursos, ${ }^{25}$ todos com viés inovador e relacionado com efetiva demanda de mercado, mudou radicalmente seus indicadores. São dados do vestibular de 2005 .. no qual não houve tratamento diferenciado para nenhum segmento da população:

a) enquanto na USP em geral o percentual de alunos egressos do ensino público é de $29 \%$, no campus USP Leste (considerado isoladamente) esse número vai a $47 \%$ (superando $80 \%$ em certos casos, no período noturno);

b) negros são $10 \%$ na USP e $21 \%$ se tomado apenas o campus Leste;

c) renda familiar de até $\mathrm{R} \$ 1.500,00$ : respectivamente $23 \%$ e $39 \%$.

$\mathrm{E}$ ainda que não houvesse nenhum tratamento favorecido para os residentes na Zona Leste da Capital e nos Municípios vizinhos, $42 \%$ dos alunos do campus Leste residem na região. número que não chega a $3 \%$ na USP em geral.

21 Em ordem decrescente: medicina, ciências biológicas. comunicaçào social (midialogia), aryuitetura e urbanismo, e farmácia.

22. Em medicina, o curso mais concorrido, esses percentuais foram respectivamente de $314 \%$ e $90 \%$.

23 No bairro de Ermelino Matarazzo. na altura do km 17 da Rodovia Airton Senna.

24 Das quais 420 no periodo noturno, o que é elemento extremamente facilitador da inclusão social.

25 Ciências da atividade física; gerontologia; gestão ambiental; gestão de politicas públicas; lazer e turismo; licenciatura em ciências da natureza; marketing; obstetricia; sistemas de informação: e tecnologia têxtil e da indumentária. 
Essa expcriência demonstra a importância da descentralização. geograficamente considerada, do ensino público universitário para que se atinja a inclusão sncial

Outro exemplo de medidas concretas que já vêm sendo implcmentadas, como alternativas às quotas, é a criação de cursinhos pré-vestibulares gratuitos para alunos da rede pública de ensino médio, com o objetivo de igualar suas condições de competir com os demais vestibulandos. ${ }^{20}$

4. Estudo de casos concretos: ensino profíssional e inclusão social

Quanto à segunda ordem de ações de inclusão social via sistema educacional (item "b" supra), uma importante medida de inclusão social é garantir alternativas que resultem em sucesso pessoal. profissional, econômico enfim, independentemente do ensino superior acadêmico.

Essas alternativas estão justamente no ensino profissional, infelizmente tão pouco difundido e valorizado no Brasil. Vige entre nós o que se puderia dizer "universitarismo" - só é valorizado o popularmente dito "doutor" aquele que ostenta um diploma superior de caráter acadêmico.

O ensino profissional, previsto na Lei de Diretrizes e Bases da Educação (Lei n. 9.394/96) ¿ regulamıntado pelo Decreto n. 5.154/04, contempla as espécies "básico", que importa qualificação para o mercado de trabalho, independentemente de escolaridade prévia; "técnico", que fornece o diploma de nível técnico para fins de determinadas habilitações profissionais; e "tecnológico" que é ensino superior de graduação, porém com enfoque no conhecimento concreto aplicado à atividade produtiva (diversamente do que acima foi chamado "ensino superior acadêmico" que tende à produção da ciència. do conhecimento abstrato, sem prejuízo. é claro de sua aplicação concreta).

Relativamente ao Estado de São Paulo, dos mais de um milhão de alunos cursando ensino superior, apenas 23 mil estão em cursos tecnológicos (sendo desses 16

26 Nesse sentido, a Universidade de São Paulo - USP ofereccu, como um projeto inicial, 5.000 vagas. em parceria com a rede estadual de educação, atuando concentradamente na Zona Leste da Capital. I: a Universidade Fstadual Paulista "Júlio de Mesquita Filho" - Uncsp iniciou projeto implantando cursinhos com oferta de 12.000 vagas no interior do Estado. E isso sem contar outras inúmeras ações, no mesmo sentido, organizadas por entidades privadas sem fins lucrativos, em particular ligadas aos estudantes das universidades públicas, como é o caso do "Cursinho do XI". mantido pelos acadêmicos da Faculdade de Direito do Largo São Francisco (USP) e do "Cursinho da POLI", dos estudantes da Escola Politécnica da USP. 
mil nas Fatec, as Faculdades de Tecnologia mantidas pelo Estado, por meio do Centro Estadual de Educação Tecnológica Paula Souza).

Essa distorção é gritante; esses números deveriam tender à igualdade. Urge, pois, ampliar-se a oferta de vagas do ensino tecnológico.

Ademais, o ensino tecnológico, sendo o ensino voltado para preparar para o trabalho, seria fundamental instrumento de inclusão social no Brasil, ainda mais face à carência de tecnólogos versus o excesso de bacharéis. ${ }^{27}$ E não se trata de hierarquizar o profissional formado em uma faculdade "acadêmica" e o profissional formado em uma faculdade de tecnologia: são vocações e atuações diversas e complementares - e igualmente importantes para o sucesso do País.

E quanto ao nível técnico, mais um exemplo concreto de medida de inclusão social - diverso das quotas - vale relatar. Até 1997, a legislação vigente previa que o diploma do ensino técnico valesse como o diploma do ensino médio convencional. Assim, quem cursasse ensino técnico, independentemente de cursar o ensino médio convencional, poderia ingressar em uma faculdade.

A partir da edição do Decreto n. 2.208, em 17 de abril de 1997, passou-se a exigir, para ingresso no ensino técnico, que o aluno estivesse simultaneamente matriculado no ensino médio convencional, ou já o houvesse concluído.

Essa medida, aparentemente criaria dificuldade de acesso ao ensino técnico, por exigir que seu aluno cumpra (simultaneamente ou não) uma dupla jornada de estudos. Porém a experiência do Estado de São Paulo, por meio das escolas técnicas mantidas pelo Centro Paula Souza - com seus 90 mil alunos - evidencia que tal medida foi causa de uma significativa ação de inclusão social.

Com efeito, o fenômeno que antes se registrava, era o de um grande percentual de alunos com melhores condições econômicas procurando as escolas técnicas do Centro Paula Souza - aliás, gratuitas - não porque tivessem a intenção de aproveitar a formação específica de técnico para buscar espaço no mercado de trabalho, mas sim para beneficiar-se de um curso "mais forte" como facilitador de acesso imediato à universidade, desprezando assim todo o investimento específico do Estado na formação de um técnico.

Com a referida mudança, esse aluno não se daria ao trabalho de cursar ensino técnico e ensino médio para ingressar imediatamente na universidade. Mais

27 Us dados do acompanhamento realizado pelo ('entro Paula Souza com seus cgressos indicam que, em 2005. $95 \%$ dos alunos das Fatec encontravam pronta colocação no mercado de trabalho, por ocasião da conclusão de seus cursos. 
simplus passou a ser cursar o éisino médio convencional e. se for o caso, um cursinho pri-vestibular.

Por outro lado, os alunos oriundos das classes menos favorcidas cconomicamente, os alunos pais de família, já mais velhos, que necessitam do ensino técnico para ingressar de pronto, ou manter-se, no mercado de trabalho, passaram a tur acesso às escolas técnicas estaduais (ainda que com a dificuldade - que de todo modo lhes reforça a formação de ter de cursar também o ensino médio convencional). E isso sem prejuízo de, futuramente, buscarem uma universidade, se assim desejarem.

Os númerus são expressivos: em 1995, 32\% dos alunos das escolas técnicas estaduais inseriam-se na faixa de renda familiar de 0 a 5 salários mínimus; apus a mudança decorrente do Decreto n. 2.208/97, esse percentual progressivamente ampliouse, atingindo, em 2002, 57\% . Nesse mesmo período, o percentual de alunos com renda familiar acima de 10 salários mínimos caiu de $28 \%$ para $10 \%$.

Quanto à faixa ctária. Em 1995, 83\% dos alunos estavam entre 15 e 17 anos (tipicamente a idade do colegial convencional), enquanto $17 \%$ estavam na faixa entre $18 \mathrm{c}$ 27 anos; e 0 acima de 27 anos. Em 2002, o percentual dos alunos entre 15 e 17 anos caiu para $24 \%$, aumentando para $57 \%$ o percentual dos alunos entre 18 e 27 anos, e para 19\% o percentual de alunos acima de 27 anos - essas últimas tipicamente idades de alunos trabalhadores.

Porém. lamentavelmente, o atual Guverno Federal revogou o Decreto $n$. 2.208:97. em que pesem os números acima expostos, que comprovam o acertu da tese. nele implícita, em favor da inclusão social.

Ao menos o Decreto n. 5.154/04, que se substituiu ao Decreto n. 2.208/97 previu a faculdade de manutenção do modelo antes vigente para a instituição que o quisessc. Disse modo, o Estado de São Paulo continuou a aplicar o modelo acima descrito ım suas escolas, mantidas pelo Centro Paula Souza.

\section{Considerações finais}

Enfim, pretendeu-se, com a análise desses casos concretos de inclusão social via sistema educacional, mostrar como a igualdade pode ser adequadamente aplicada, conforme o critério de justiça que a embase.

A igualdade - repitam-sc os pressupostos de inicio enunciados - há que ser vista como meio de se garantir liberdade para todos. E a liburdade, qualidade essencial do individuo, deve ser reconhecida como valor central dos direitos humanos. 
A aplicação da igualdade com o adequado critério de justiça é mecanismo essencial para qualquer regime democrático e modo de se garantir a liberdade. Já a aplicação desmedida da igualdade tende a conduzir o regime político para igualitarismos de tendência totalitária, nos quais o valur do ente coletivo anula o valor do indivíduo, suprimindo-se sua liberdade.

E, para concluir, lembrem-se as lições de Jorge Miranda, ${ }^{28}$ ao apontar que a experiência histórica mostra que "a conquista du igualdade não se tem conseguido tanto em abstruto quanto em concreto, atravis da eliminaçũo ou da redução de sucessivas desigualdades ou da extensão de novos beneficios; e tem sido firulo yuur da difusão das idéias quer das lutas pela igualdade travadas por aqueles que si encontravam em sifuaçõu's de marginalização. opressão e exploração"

São Paulo, dezembro de 2005.

\section{Ruferências}

ALMEIDA, lernando Dias Menezes de. Liberdade de Reunião. São Paulo: Max Limonad, 2001.

BERLIN. Isaiah. Dois Conceitos de Liberdade. In: QUATRO Ensaios sobre a Liberdade. Trad. Wamberto Hudson Ferreira. Brasília: Universidade de Brasília, 1981.

BOBBIO, Norberto. Igualdady Libertad. Trad. Pedro Aragón Rincón. Barcelona: Paidós, 1993.

CRUZ, Carlos Henrique de Brito. Universidade Pública: O Mito do Elitismo. O Estado de São Paulo. em 18/01/2004. . Inclusão Social com Valor Acadêmico. O Estado de São Paulo, 03/06/2004.

FERREIRA FII.HO, Manoel Gonçalves. Curso de Direito Constillucional. São Paulo: Saraiva, 1997. MIRANDA. Jorge. Manual de Direito Constitucional. Coimbra: Coimbra, 2000. Tomo IV: PECES-BARBA, Gregorio. Curso de Derechos Fundamentales. Madrid: EUDEMA, 1991.

\footnotetext{
28 MIRANDA. Jorge. Manual de Direiti Constitucional. Coimbra: Coimbra, 2000. Tomo IV, p. 227.
} 